\title{
A THOUGHT FROM OUR CHAIR
}

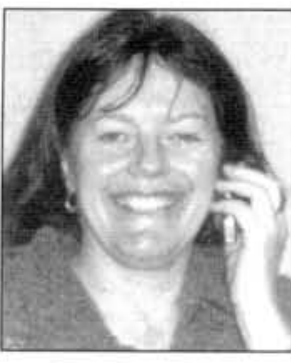

Pat Smedley
We are delighted to announce that we have a new president of the association : Dr AnnaMaria Rollin: Consultant Anaesthetist at Epsom \& St Helier NHS Trust. Dr Rollin is closely involved in key projects at the Royal College of Anaesthetists and believes strongly that many recovery \& anaesthetic nurses have a wealth of critical clinical skills and could be better developed professionally. We look forward to working with her to raise the profile and scope of practice of recovery/anaesthetic nurses. Dr Rollin will officially take over as President at this years June conference.

BARNA has been involved recently in two important initiatives (more inside the News Section of the Journal). NWWA (New Ways of Working in Anaesthesia: NHS Changing Workforce Programme) promises the chance to trial non-physician provision of anaesthesia at chosen sites around the country. This is a very exciting development for all anaesthetic (and indeed all critical care) nurses who want to develop their critical skills.

The Perioperative Care Collaborative is a joint venture by all the professional associations concerned with perioperative care to exchange ideas and speak with one (more authoritative voice) about key issues. A welcome venture all professional associations share many of the same concerns and the chance to share ideas is welcome.

A mailshot has gone out to all members with the invitation to comment on the first draft of our standards document. Standards will be presented at conference and we would hope to be able to vote on them by this time. We have also sent a 'Willingness to Serve form' for those practitioners really interested in developing their speciality. I would love to hear from you get back to me.

By the time this letter is published I will have returned from another ASPAN conference in Albuqueque New Mexico. A great venue for what I am sure will be an excellent conference. I will almost certainly bring back new ideas for our association and pave the way for our welcome to the ASPAN nurse leaders in Hove this June. They are excited about their forthcoming trip - and about our potential to grow as an Association.

For those of you who will be able to come to conference we have put together quite a few different ideas. Venue first - we have never been to the South coast but we felt that mid summer in a seaside town was definitely appealing. This does not mean that the conference will be permanently placed in the South. Ideally it should travel every year -or two years - north south - midlands - to give everyone a fair chance to attend at some stage. Regional variation also gives key recovery/anaesthetic units a chance to play a major role in setting up conference as hosts working with our team. Another first is the provision of a hands-on workshop - we have long wanted to do this and we felt that practical airway management was the obvious key 'skill' to be tackled. We have also for the first time put on 5 tracks -2 main lectures and smaller group sessions covering a multitude of clinical and management issues. And another first- no disco! Instead an early evening informal wine and canapes reception leaving delegates the chance to explore the night life in Brighton later on.

Finally I would like to thank the BARNA committee for all the hard work they have put in throughout this year in running this association and putting together what will be an excellent conference. They are all very busy people with full time work commitments but manage to give up their valuable time for this association. Thank you.

Pat Smedley 